\title{
Detached aquaculture buoys in the SE Pacific: potential dispersal vehicles for associated organisms
}

\author{
Juan Carlos Astudillo ${ }^{1}$, Macarena Bravo ${ }^{1}$, Clément P. Dumont ${ }^{1,2,3}$, Martin Thiel ${ }^{1,2, *}$ \\ ${ }^{1}$ Facultad de Ciencias de Mar, Universidad Católica del Norte, Larrondo 1281, Coquimbo, Chile \\ ${ }^{2}$ Center of Advanced Studies in Arid Zones (CEAZA), Coquimbo, Chile \\ ${ }^{3}$ Present address: The Swire Institute of Marine Science and Department of Ecology and Biodiversity, \\ The University of Hong Kong, Hong Kong SAR
}

\begin{abstract}
Throughout the world's oceans a wide variety of floating plastics are found, among which buoys stand out for their high floatability and diversity and abundance of associated organisms. Between 2001 and 2005, we conducted 25 ship surveys in the Bay System of Coquimbo (BSC), during which we registered 34 detached buoys floating between 1 and $45 \mathrm{~km}$ from the coast. The objective of this study was to infer the possible origin of these buoys, identify the associated biota and characterize their biological traits. Short-term drift experiments (30 min) showed that buoys without rope responded primarily to the velocity and direction of the wind, while buoys with ropes $(3 \mathrm{~m}$ length) followed surface currents. Using the wind velocity and direction during the $12 \mathrm{~h}$ before capture of the detached buoys, we estimated the hypothetical trajectories of these buoys during that time period. Results indicated that most buoys originated from aquaculture facilities in the BSC. A total of 134 different species from 14 phyla was found on 18 anchored (91 species) and 22 detached (116 species) buoys sampled. Community composition was similar among buoys $-54 \%$ of all species were common for anchored and detached buoys-but a higher number of rare species occurred on detached buoys. Buoys do not seem to lose but rather gain organisms after detachment. The most common functional groups on these buoys were mobile species, suspension-feeders and species with sexual reproduction, separate sexes, internal fertilization and direct or very short larval development. Fouling communities on detached buoys were mostly in advanced successional stages, comprising diverse species (including several non-indigenous species) adapted to the conditions at the sea surface. These results suggest that floating buoys may transport associated species over extensive distances, thereby also contributing to the spread of non-indigenous species.
\end{abstract}

KEY WORDS: Rafting · Dispersal · Buoys · Floating plastics · Fouling communities · Succession · Non-indigenous species $\cdot$ Chile

\section{INTRODUCTION}

The explosive increase of floating plastic debris in the oceans has raised concerns due to unprecedented levels of rafting opportunities for many organisms that are likely to be dispersed throughout the world's oceans (Winston et al. 1997, Barnes 2002). Rafting on plastics has been identified as a potential dispersal mechanism for a wide variety of organisms, including bryozoans (Winston 1982, Stevens et al. 1996), hydrozoans (Barnes 2002) and barnacles (Barnes \& Milner
2005). The persistence of floating objects at the sea surface and selective processes on associated organisms during these journeys have important implications for rafting dispersal.

Among the floating plastics are bottles, packing material, plastic bags, fishing nets, pellets and buoys (Jara \& Jaramillo 1979, Pruter 1987, Thiel et al. 2003b, Thiel \& Gutow 2005a, Ivar do Sul \& Costa 2007), mostly originating from shipping, fishing, industrial production and touristic activities (Pruter 1987, Derraik 2002, Gregory \& Andrady 2003). During the past 2 decades, 
the continuous growth of aquaculture activities has led to a further substantial increase of plastic ropes, floats and buoys in the oceans. These objects, used to hold suspended cultures, occasionally detach from bottom anchors and then can float over long distances (Jara \& Jaramillo 1979, Thiel et al. 2003a) before finally ending up on beaches or being battered onto rocky shores (Gregory \& Andrady 2003, Scarabino 2004, Fujieda \& Sasaki 2005).

The potential distance travelled by floating items depends on their floating time (Thiel \& Gutow 2005a). Plastics have a high buoyancy (low density) and high durability (Derraik 2002, Gregory \& Andrady 2003), but a heavy load of fouling organisms, penetration of water and stranding on the beach can reduce their floating time (Ye \& Andrady 1991, Thiel \& Gutow 2005a). One way of estimating the distance an item has travelled at sea is tracing it back to its site of origin. With industrial items, the country of origin can sometimes be inferred based on production labels (Winston 1982, Mora et al. 2001). Even items lost in large numbers from ships can be traced back to their site of origin (Ebbesmeyer \& Ingraham 1992). Transport of these objects at the sea surface has primarily been related to oceanic currents (Winston 1982, Mora et al. 2001); however, wind may also play an important role in the displacement of these objects, in particular those with high buoyancy and a large proportion of their volume above the sea surface (Harrold \& Lisin 1989, Aliani \& Molcard 2003, Muhlin et al. 2008). Using data from wind velocity and direction as well as measurements of currents, we can roughly infer the probable sites of origin.

A wide diversity of organisms can travel on these floating objects between distant locations. Present knowledge of the organisms transported via floating plastics is largely based on objects stranded on beaches, where many mobile and soft-bodied species might have disappeared quickly after stranding (Jokiel 1989, Scarabino 2004). This results in a possible bias of published reports towards sessile species with hard skeletons such as foraminiferans, bryozoans, hydrozoans, barnacles and serpulid polychaetes (Winston 1982, Barnes 2002, Scarabino 2004, Barnes \& Milner 2005). Indeed, approximately $86 \%$ of the rafting organisms reported from plastics are sessile species and $90 \%$ of these are suspension-feeders with the ability to hang onto the substratum, feed and develop persistent local populations (Thiel \& Gutow 2005b). Further, sessile suspension-feeders with asexual reproduction, internal fertilization or direct development combine biological traits that favour the successful colonization of artificial substrata such as plastics (Thiel \& Gutow $2005 b)$. However, the proportion of sessile suspensionfeeders is probably overestimated given that these also offer a substratum for a large number of mobile species such as crustaceans, molluscs, polychaetes, nemerteans and echinoderms (e.g. Cerda \& Castilla 2001, Hernández et al. 2001, Sepúlveda et al. 2003, Thiel et al. 2003a). These mobile species are likely underestimated among the currently known rafting biota on floating plastics because they quickly disappear after an object is stranded on the beach.

For similar reasons, the reproductive biology of organisms associated with floating plastics is not well known. On remote seamounts, many species with direct development are present, suggesting that they covered the long distance from potential source regions via rafting (Parker \& Tunnicliffe 1994). Rafting was also an argument used to explain the Rockall paradox, namely that a direct developing species is found on an oceanic island while a congener with planktonic larvae is missing (Johannesson 1988). We can similarly expect that the proportion of species with direct development or a larval duration of $<2 \mathrm{wk}$ prevails on floating objects, in particular if items have been afloat for long periods of time.

Among the diverse types of plastics that can serve as transport vectors for organisms, plastic buoys (used in aquaculture, harbours and touristic installations) have a very high floating potential. High buoyancy and durability facilitates their persistence at the sea surface and over long-distance trips influenced by prevailing winds. Reports of organisms on buoys outside their distribution range further indicate long-distance dispersal (Jara \& Jaramillo 1979, Scarabino 2004). Buoys are also often colonized by fouling organisms considered as eco-engineers (e.g. bryozoans, barnacles and solitary tunicates), which create ample habitat for mobile species that otherwise could not colonize the smooth surface of plastic buoys (Tsikhon-Lukanina et al. 2001, Cocito 2004, Greene \& Grizzle 2007).

Floats and buoys are often most abundant in areas with high aquaculture activity (Fujieda \& Sasaki 2005, Hinojosa \& Thiel 2009). Since many of these buoys are colonized while anchored in coastal waters, they generally carry a very diverse and abundant fouling biota, yet so far no systematic studies on the organisms growing on free floating buoys has been conducted. During several years of seasonal ship surveys, we frequently encountered detached buoys floating within the Bay System of Coquimbo (BSC). To infer the possible origin of these buoys, we determined the effect of wind and surface currents on the displacement of freely floating buoys at the sea surface. We then examined whether the fouling communities on detached buoys were similar to those on anchored buoys in the BSC. To reveal which organisms are most likely to be transported via detached buoys, we further characterized the mobility, feeding type, reproductive biology and developmental mode of species found on the buoys. 


\section{MATERIALS AND METHODS}

Study site and buoy sampling. Buoys were sampled in the BSC on the northern-central coast of Chile (Fig. 1). Throughout the BSC there are several smaller bays with large numbers of buoys: in the southern part are the semi-enclosed bays of Tongoy and Guanaqueros with intense scallop aquaculture, and in the central part are the ports of Bahía La Herradura and Coquimbo with important harbour activities. Tidal variations in these semi-enclosed bays influenced by semidiurnal tides have only minor effects on surface currents, which are mainly driven by winds (ValleLevinson et al. 2000, Valle-Levinson \& Moraga 2006); outside of the inner bays, i.e. in the coastal waters where most buoys were collected, tides do not affect surface currents (M. Ramos pers. comm.). More importantly, the region of Coquimbo is characterized by predominant winds from the west and southwest with velocities of 7.2 to $46.0 \mathrm{~km} \mathrm{~h}^{-1}$ (Moraga \& Olivares 1993). Further, this region is under the influence of the coastal branch of the Humboldt Current System, with surface waters moving towards the north and northwest at a velocity of $\sim 1.0 \mathrm{~km} \mathrm{~h}^{-1}$ (Marín \& Delgado 2007), and 2 upwelling zones in proximity to Punta Lengua de Vaca and Punta de Choros (Rutllant \& Montecino 2002).

The detached buoys analysed in the present study were collected as we encountered them by chance during 25 ship surveys primarily aimed at estimating the abundance of floating algae during the years 2001 to 2005 (Table 1). The surveys started at the opening of Bahía La Herradura (Fig. 1), followed a track through the northwest or southwest sector of the BSC, and
Table 1. Ship surveys during the years 2001 and 2005, the number of buoys registered during each survey and the total area surveyed. ${ }^{*}$ Buoy(s) not sampled

\begin{tabular}{|lccc|}
\hline Cruise & Date & No. buoys & Area surveyed $\left(\mathrm{km}^{2}\right)$ \\
\hline 1 & 18-Dec-01 & $1^{*}$ & 49.86 \\
2 & 19-Dec-01 & 0 & 30.51 \\
3 & 13-Feb-02 & 0 & 64.92 \\
4 & 14-Feb-02 & 0 & 16.50 \\
5 & 11-Jun-02 & 2 & 50.43 \\
6 & 12-Jun-02 & 3 & 45.10 \\
7 & 25-Jun-02 & $1^{*} 1^{*}$ & 84.34 \\
8 & 10-Sep-02 & $1^{*}$ & 49.06 \\
9 & 26-Sep-02 & 0 & 43.85 \\
10 & 30-Dec-02 & $1^{*} 1^{*}$ & 139.76 \\
11 & 23-Apr-03 & 0 & 42.14 \\
12 & 25-Apr-03 & 0 & 49.55 \\
13 & 29-Jul-03 & $1^{*}$ & 37.80 \\
14 & 15-Oct-03 & $1^{*}$ & 46.90 \\
15 & 17-Oct-03 & $1^{*}$ & 29.16 \\
16 & 13-Jan-04 & 0 & 48.76 \\
17 & 14-Jan-04 & 0 & 47.83 \\
18 & 04-May-04 & 0 & 46.06 \\
19 & 05-May-04 & $12,2^{*}$ & 51.59 \\
20 & 30-Jun-04 & $1^{*}$ & 86.21 \\
21 & 07-Oct-04 & 1 & 55.94 \\
22 & 04-Jan-05 & $1^{*} 2^{*}$ & 48.91 \\
23 & 05-Jan-05 & 0 & 50.22 \\
24 & 12-Apr-05 & 1 & 43.93 \\
25 & 13-Apr-05 & 0 & 32.86 \\
\end{tabular}

returned to the starting point. Every hour the ship stopped to record the wind velocity and direction and air temperature (Fig. 1). We estimated the total area covered during the surveys, based on the length and width of the ship transects, using GIS (ArcView GIS 3.3) (Table 1). The width of transects was estimated at
Fig. 1. Bay System of Coquimbo (BSC) with the oceanographic stations used in the present study (triangles) and areas with anchored buoys (black)

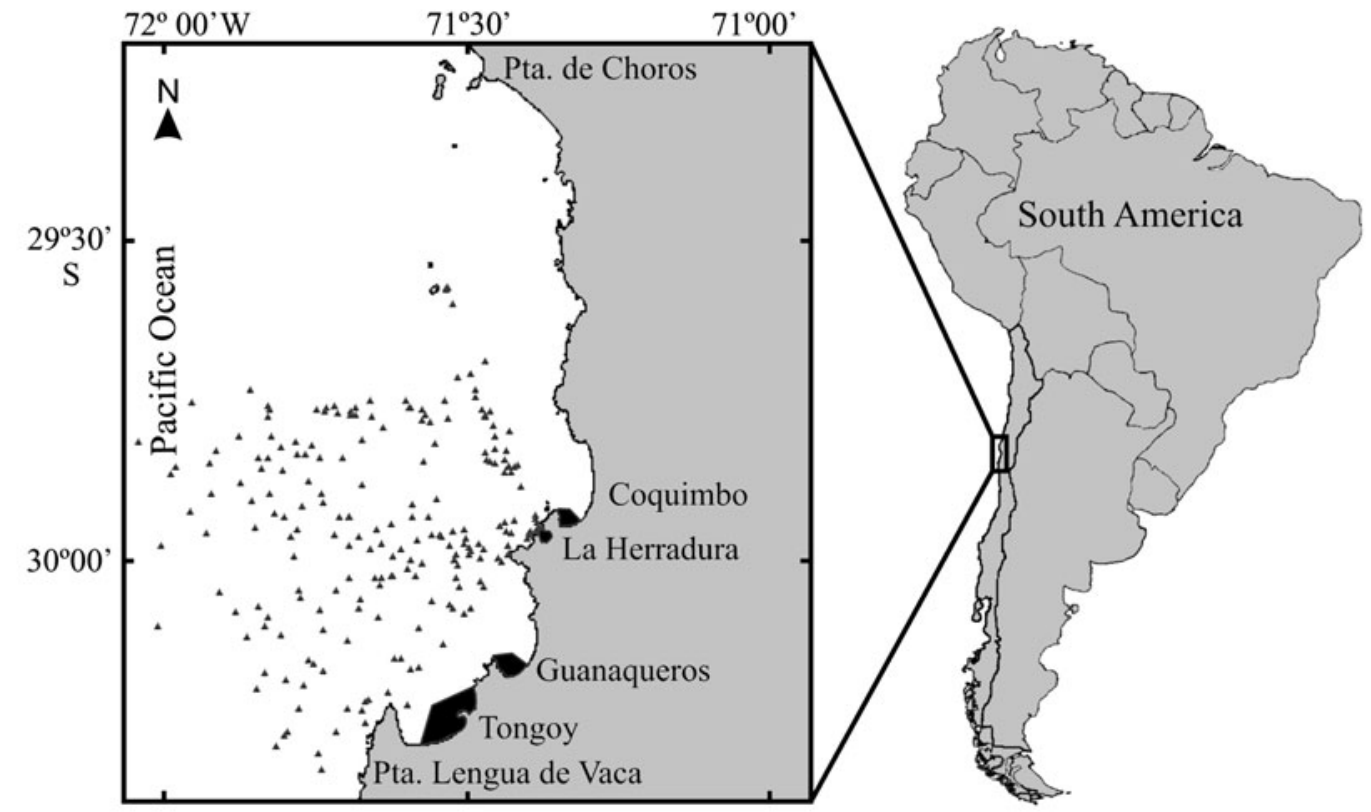


$0.4 \mathrm{~km}(0.2 \mathrm{~km}$ on each side of the ship) because this is an appropriate distance for adequate identification of floating buoys. The collected plastic buoys had a volume of $14 \mathrm{l}$ and a spherical shape with a smooth black surface area, which are commonly used for aquaculture purposes. Clean buoys without any attached ropes have about $95 \%$ of their total volume emerged above the sea surface. We consequently tested whether prevailing winds affected velocity and drift direction of these buoys (see below).

The geographic positions of all buoys seen during the surveys were registered with a GPS, and those in proximity to the ship were collected together with their associated biota. We also sampled 18 anchored buoys in Bahía de Tongoy ( 3 in October and 3 in November 2007, 5 in August and 7 in October 2008) to obtain information on the biota of anchored aquaculture buoys. For buoys (detached and anchored) with dense aggregations of organisms, a representative subsample of large epibionts together with their associated fauna was sampled. Buoys with moderate fouling aggregations were sampled entirely. The buoys or large aggregations were preserved in 5\% formalin in large plastic bags. Later the biota was carefully scraped off the buoys and preserved in $70 \%$ ethanol.

Displacement and origin of detached buoys at the sea surface. To determine the effect of wind on the buoys at the sea surface, we released buoys with and without ropes (rope of $3 \mathrm{~m}$ length with a small cement weight of about $500 \mathrm{~g}$ at its end) under different wind conditions. In order to determine the role of currents on the trajectory of the buoys, we also released oceanographic drifters with a polyethylene panel $(70 \times$ $50 \mathrm{~cm}$ ) submerged at a water depth of about $30 \mathrm{~cm}$. The buoys and drifters were left floating for approximately $30 \mathrm{~min}$; for each buoy and drifter we registered the release and recapture point. During this experiment we measured the velocity and direction of the wind at 5 min intervals with a handheld anemometer and a compass. Using the GPS data and ArcView GIS 3.3, we determined the distance and direction of displacement, and based on the floating time between release and recovery we calculated the velocity for each buoy and drifter. This experiment was conducted at 3 different sites: (1) in Bahía La Herradura on 12 August 2006, 4 buoys without rope; (2) outside of Bahía La Herradura on 26 September 2006, 3 buoys with rope, 3 buoys without rope and 3 drifters (repeated 3 times); (3) offshore Tongoy on 10 January 2008, 9 buoys with rope, 10 buoys without rope and 6 drifters.

We tested the directionality of displacement of the buoys with the wind and surface currents during each trial. We converted the directional data to the deviation angle corresponding to the difference between the buoy's trajectory and the wind/current direction and used the modified Rayleigh test to determine the specified mean directional angle (Zar 1999). To examine the relationship between the velocity of the buoys and that of the wind and surface currents, we used linear regression analyses. The data from 10 January 2008 were not used for this analysis because recovery of the buoys required more time than planned (due to unfavourable sea conditions and high velocity of the buoys) and the wind velocity increased during that time (but had only been monitored at the beginning of the experiment).

Using the relationship between the trajectory of the experimental buoys and the direction and velocity of wind, we estimated the hypothetical trajectories of the detached buoys collected during the ship surveys in the BSC. Hypothetical trajectories were estimated for the $12 \mathrm{~h}$ before capture, which was considered sufficient because 28 of the 34 registered buoys were found within $20 \mathrm{~km}$ of the nearest coast, and a review of diverse studies suggested that most floating objects travel at velocities of 0.5 to $1 \mathrm{~km} \mathrm{~h}^{-1}$ (Thiel \& Gutow 2005a). Estimates were based on the relationship between wind and buoys without rope (see 'Results') because most of the detached buoys did not have a rope attached. For 13 buoys we used the wind data obtained from a meteorological station at Punta Lengua de Vaca (see Fig. 1), and for 20 buoys we used the wind data recorded during the ship surveys (no data were available from the meteorological station during some periods). A preliminary comparison showed that the wind directions recorded on the ship and at the meteorological station were similar (Moore's test; $R_{0.05,50}=0.651, \mathrm{p}>0.1$; Zar 1999). For 1 of the 34 registered buoys, no wind data were available (due to equipment failure); consequently, this buoy was not included in the analyses. In the reconstruction of the hypothetical trajectories we used Arc View GIS 3.3 and assumed that buoys moved mainly with the wind (see 'Results'). For the trajectories of the buoys for which we only had wind data from the ship surveys (i.e. only for a few hours before capture), we extrapolated those wind data to cover the entire $12 \mathrm{~h}$ period before capture. In order to estimate whether the hypothetical trajectory of a buoy points to local bays, we identified the straight line from the collection location of the buoy to the nearest bay with anchored buoys within the BSC. For each buoy, the deviation angle formed by the buoy's hypothetical trajectory and the straight line to the nearest bay was identified. The deviation angle of buoys collected southwest of Punta Lengua de Vaca was calculated from the tip of the peninsula. To test the hypothesis that buoys have their origin in local bays, we examined whether the mean deviation angle of the buoys differed significantly from $0^{\circ}$ using the modified Rayleigh test. 
Characterization of buoy-associated biota. Taxonomic identification and abundance estimates: Samples were washed over a sieve $(250 \mu \mathrm{m})$ and subsequently sorted under a dissecting microscope. All organisms were separated and identified to the lowest possible taxonomic level using specialized literature (see Appendix 1, www.int-res.com/articles/suppl/b005 p219_app.pdf) and the help of taxonomic experts. We estimated the relative abundance of each species in the following way: (1) mobile organisms, number of individuals; (2) solitary sessile organisms, number of individuals and wet weight (g); and (3) colonial sessile organisms, wet weight. We only considered the soft parts of species with calcareous structures (e.g. the barnacle Austromegabalanus psittacus and the mussel Semimytilus algosus) to avoid an overestimation of their biomass, because these species have a high biomass relative to surface area compared to other sessile species such as hydrozoans and bryozoans. All sessile organisms were air-dried for $5 \mathrm{~min}$ on a sieve before weighing. The number of individuals was determined on a semi-quantitative scale using the following ranges of abundance: 1 to 10,11 to 100,101 to 1000 and $\geq 1001$ individuals per sample. In a similar way, we established the following ranges for wet weight estimates: $<0.9,1.0$ to $9.9,10.0$ to 99.9 and $\geq 100.0$ g per sample.

Community composition and biological traits: To determine if the sample size of detached and anchored buoys was representative of the species present in these communities, we examined species accumulation for each type of buoy (detached and anchored) and generated the corresponding curve using the estimate S (bootstrap method with replacement; PRIMER 6, Plymouth Marine Laboratory). We then compared the composition (presence-absence data) of fouling communities with multivariate analyses of similarities (ANOSIM; Clarke \& Warwick 1994). To visualize multivariate patterns, non-metric multidimensional scaling (nMDS) ordinations were done. PRIMER 6 was used for ANOSIM and nMDS analyses. Furthermore, we used contingency tables to compare the number of species per phylum between anchored and detached buoys.

The fauna found on detached and anchored buoys was characterized according to mobility, feeding mode, reproductive biology (reproductive mode, sexual system and fertilization) and planktonic duration. For some species the biological traits were based on knowledge of other species from the genus or family; species for which no information was available were not considered in the analyses. All organisms were classified according to their mobility into sessile, semisessile and mobile categories. The following feeding modes were identified: suspension-feeders, depositfeeders, herbivores and carnivores (predators and scavengers). For reproductive mode we distinguished species with sexual, asexual or mixed strategy. For sexually reproducing species we further distinguished gonochoric and hermaphroditic species. Fertilization was classified into internal (within the female's reproductive tract, on the body of the female or in capsules produced by her) and external, where males and females release gametes into the water column. Planktonic duration was estimated according to the residence of the larvae in the water column based on categories used by Parker \& Tunnicliffe (1994): (1) direct, where a juvenile emerges from the egg; (2) short, where larval development takes $<2 \mathrm{wk}_{i}$ (3) intermediate, with larvae that remain 2 to $8 \mathrm{wk}$ in the plankton; and (4) long, with larvae that remain $>8 \mathrm{wk}$ in the plankton before settling.

Proportions were calculated on all species for each group of buoys (detached and anchored) for which information on functional type was available. To examine whether detached buoys had biological traits similar to anchored buoys in the BSC, we used contingency tables to compare the proportions of the different functional types.

Relationship between sessile and mobile species: To test whether sessile species facilitate the colonization of mobile species, we examined the relationship between these 2 groups by comparing the number and biomass of sessile species with the total number of mobile species in each sample. For the sessile species we only included those with a wet weight $>1 \mathrm{~g}$. This relationship was carried out with both detached and anchored buoys. The relationship was described with a logarithmic regression and significance of the correlations was examined using a Student's $t$-test.

\section{RESULTS}

\section{Displacement and origin of buoys}

The direction of displacement of the experimental buoys without rope was strongly influenced by wind direction $\left(u_{0.05,22}=6.458, \mathrm{p}<0.0005\right.$; mean deviation angle $\left.=1.7^{\circ}\right)$. However, no clear relationship was observed between wind direction and either the displacement of buoys with rope $\left(u_{0.05,19}=-0.285, \mathrm{p}>0.25\right.$; $\left.-95.3^{\circ}\right)$ or surface drifters $\left(u_{0.05,15}=0.369, \mathrm{p}>0.25\right.$; $-83.6^{\circ}$ ) (Fig. 2A). In contrast, the displacement of surface drifters was similar only to the direction of experimental buoys with rope $\left(u_{0.05,19}=6.064, \mathrm{p}<0.0005\right.$; $6.0^{\circ}$ ) (Fig. 2B). Similarly, the velocity of buoys without rope was positively related to wind velocity $\left(t_{0.05(2), 11}=\right.$ $8.811, \mathrm{p}<0.001)$ and the buoys with rope to the surface drifters $\left(t_{0.05(2), 17}=5.560, \mathrm{p}<0.001\right)$ (Fig. 2C,D). The velocity of buoys without rope varied between 0.8 and 

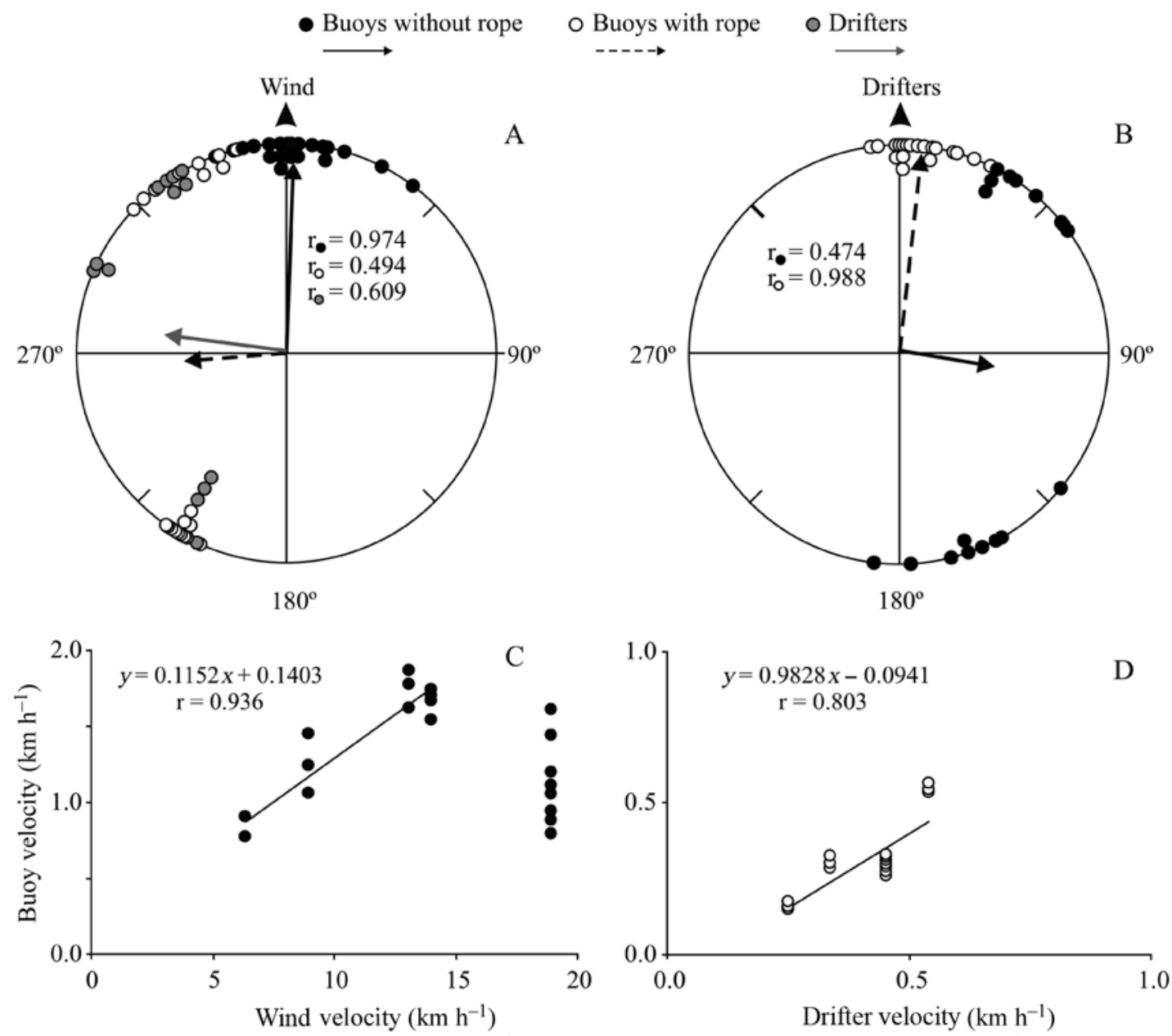

Fig. 2. (A) Displacement direction of buoys with and without rope and of drifters in relation to the prevailing wind (set as $0^{\circ}$ ) during the experiments. (B) Displacement direction of buoys with and without rope in relation to the prevailing surface current (set as $0^{\circ}$ ) during the experiments. (C) Relationship between the velocity of the prevailing wind and the velocity of the buoys without rope. Buoys from the experiment in Tongoy (line of data points on the right of the graph) were not included in the regression because the period between release and recovery lasted very long (due to unfavorable sea conditions) and wind velocity changed during that time period. (D) Relationship between the velocity of surface currents (drifters) and the velocity of buoys with rope

$1.9 \mathrm{~km} \mathrm{~h}^{-1}$ at wind velocities of 6.4 to $14.0 \mathrm{~km} \mathrm{~h}^{-1}$, while buoys with rope and drifters had a slower and similar velocity range ( 0.2 and $0.6 \mathrm{~km} \mathrm{~h}^{-1}$, respectively).

The hypothetical trajectories based on the wind during the $12 \mathrm{~h}$ prior to collection of the detached buoys indicate that 15 buoys moved southwest, another 14 buoys northeast, 2 northwest and 2 southeast (Fig. 3A). The length of the displacement vectors estimated for the buoys varied from 4 to $33 \mathrm{~km}$ in $12 \mathrm{~h}$. The buoy closest to the coast was found $1 \mathrm{~km}$ from the shore and the farthest at $45 \mathrm{~km}$. Six of the 13 buoys for which data from the meteorological station were available had experienced wind velocities $>40 \mathrm{~km} \mathrm{~h}^{-1}$ during the $48 \mathrm{~h}$ before we recorded them as detached buoys in the BSC.

The test conducted to determine whether the detached buoys originated in the BSC indicates a significant relationship, using the angle of the hypothetical trajectory and the line to the nearest bay $\left(u_{0.05,33}=5.170, \mathrm{p}<0.001\right)$. Detached buoys for which we could identify a hypothetical trajectory (Fig. 3A) had a mean deviation angle of $23.3^{\circ}$ from the nearest bay (Fig. 3B), suggesting that a large proportion of the buoys could indeed have their origin in one of the bays from the BSC. Three buoys had a deviation angle $>90^{\circ}$, which indicates that they probably come from other, more distant areas (Fig. 3A,B).

\section{Buoy-associated biota}

Taxonomic diversity

A total of 134 species were recorded on the 22 detached and 18 anchored buoys sampled in the BSC (Appendix 1). On the detached buoys we found 116 


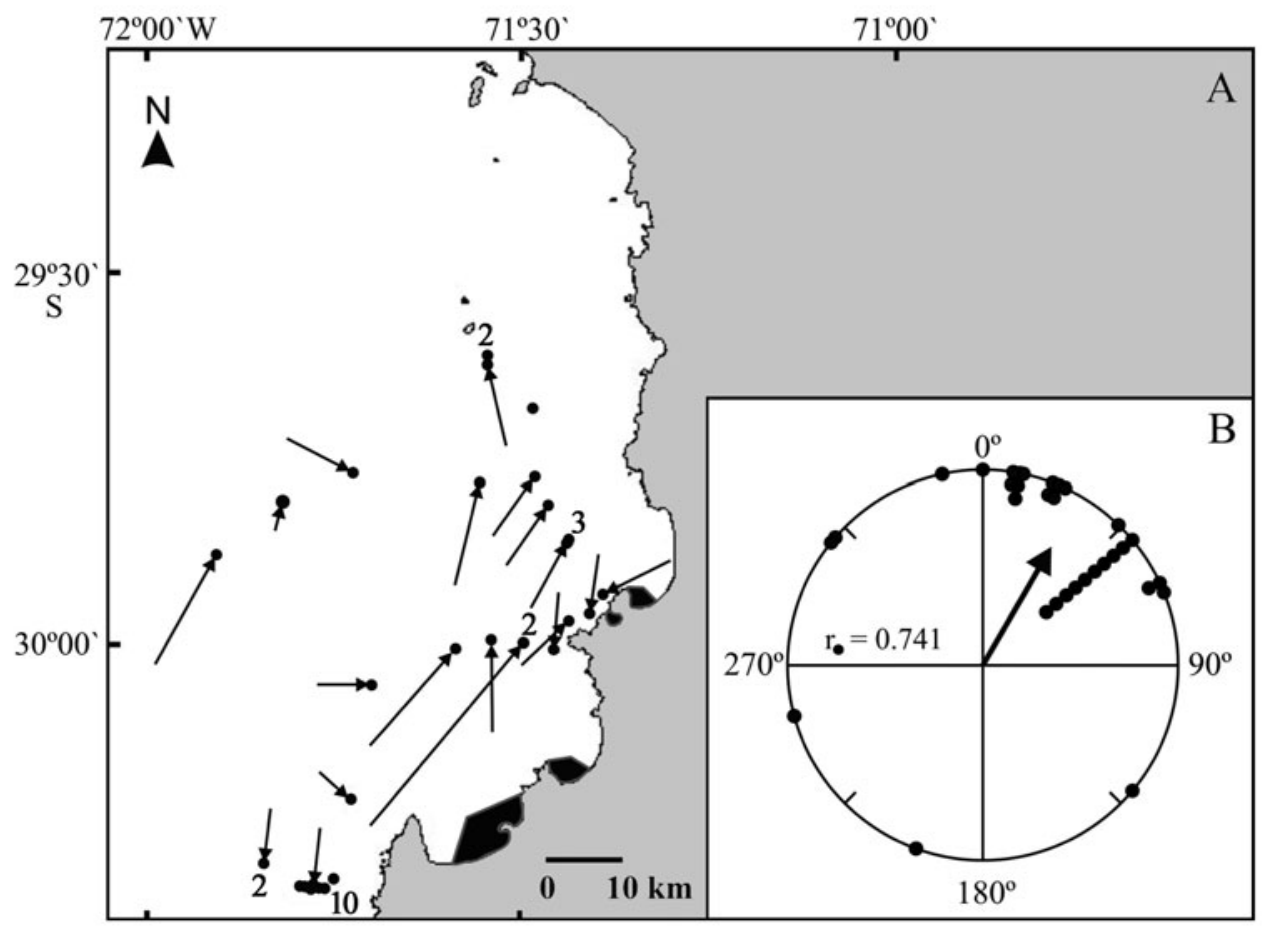

Fig. 3. (A) Hypothetical trajectories of 33 detached buoys during the $12 \mathrm{~h}$ before their floating position (•) was identified during ship surveys conducted between 2001 and 2005 (dot without arrow: position of one buoy for which we have no wind data, and thus could not estimate the hypothetical trajectory). Numbers indicate the number of buoys associated with the same vector. Black areas as in Fig. 1. (B) Angle between hypothetical trajectory (during $12 \mathrm{~h}$ before localization) and the line to the nearest bay with anchored buoys (black area in A) for the 33 buoys with hypothetical trajectories. Arrows: significant resultant vector (r) of modified Rayleigh's tests

species pertaining to 14 phyla, including 12 plants/ algae (4 phyla), while on the anchored buoys we found 91 species from 13 phyla (Table 2). Among the invertebrates, the phylum Arthropoda, followed by Annelida and Mollusca, dominated on both detached and anchored buoys. Of the 134 species found, 73 were

Table 2. Number of species in each phylum found on detached and anchored buoys

\begin{tabular}{|lcc|}
\hline & \multicolumn{2}{c|}{ No. species } \\
Phylum & Detached buoys & Anchored buoys \\
\hline Chlorophyta & 3 & 3 \\
Ochrophyta & 3 & 5 \\
Rhodophyta & 5 & 1 \\
Magnoliophyta & 1 & 0 \\
Porifera & 2 & 1 \\
Cnidaria & 8 & 5 \\
Platyhelminthes & 5 & 5 \\
Nemertea & 3 & 1 \\
Annelida & 19 & 14 \\
Arthropoda & 38 & 34 \\
Mollusca & 17 & 13 \\
Echinodermata & 2 & 2 \\
Chordata & 3 & 3 \\
Bryozoa & 7 & 4 \\
Total & 116 & 91 \\
\hline
\end{tabular}

common for detached and anchored buoys. We recorded 42 and 23 species which only appeared once on detached and anchored buoys, respectively.

\section{Community composition and biological traits}

The number of accumulated species from the buoys sampled indicates that the sample size was representative for anchored buoys but failed to fully sample rare species on detached buoys (Fig. 4A). The number of species per phylum was similar between anchored and detached buoys $\left(\chi_{0.05,13}^{2}=5.59, \mathrm{p}=0.96\right)$. The comparison of presence-absence data showed no clear differences, with a similar community composition on detached and anchored buoys (ANOSIM, global R = $0.19, \mathrm{p}=0.001$ ). The $\mathrm{nMDS}$ revealed 5 detached buoys different from the group of detached and anchored buoys (Fig. 4B); these buoys had communities with only 1 sessile species $>1 \mathrm{~g}$ and few mobile associate species (<18 overall species). In contrast, half of the detached and anchored buoys contained over 30 species per buoy (Fig. 4C). The highest species richness was 42 and 50 and the lowest 6 and 20 on detached and anchored buoys, respectively. 

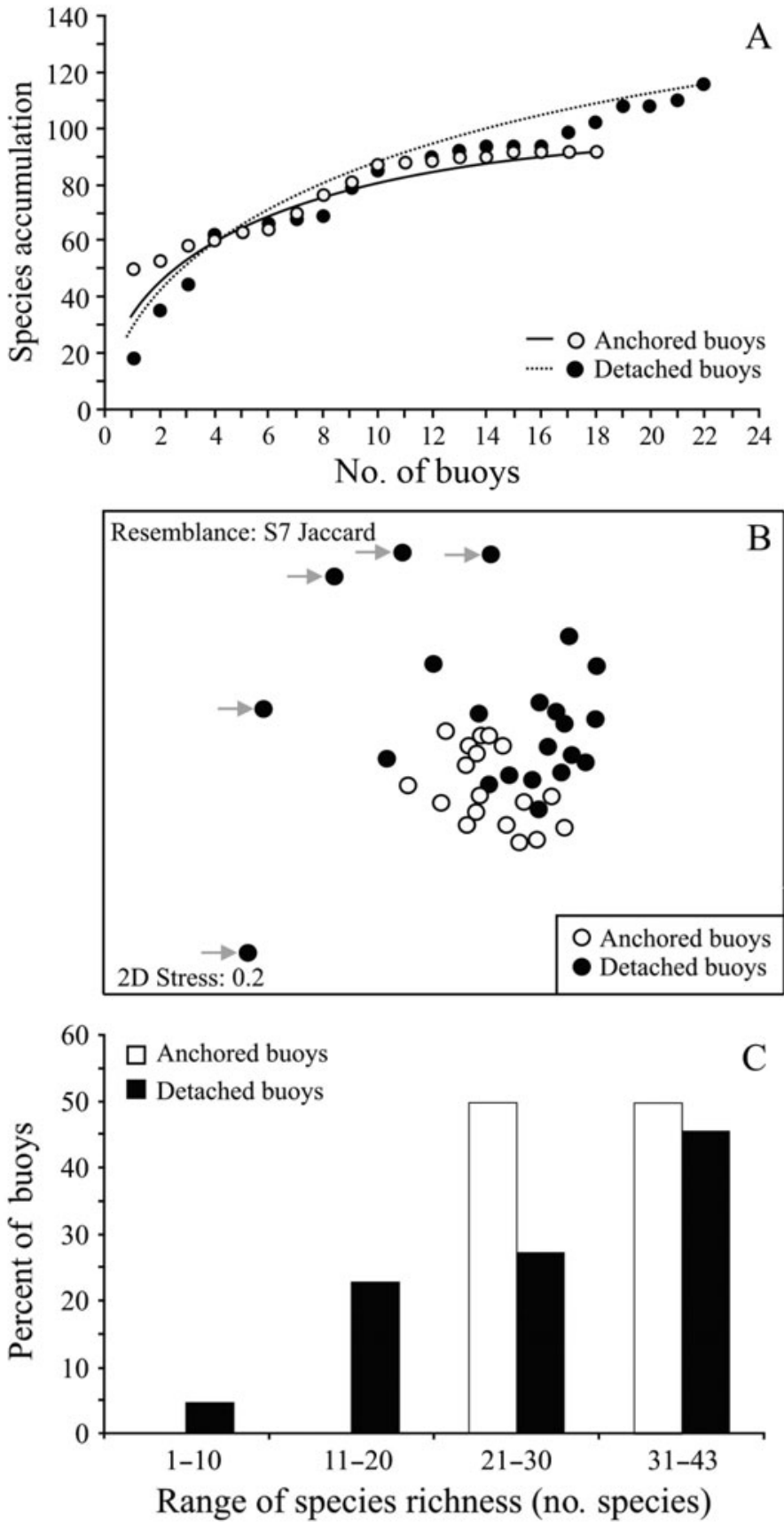

Fig. 4. (A) Species accumulation per unit of buoys sampled. The lines represent the curves generated using the estimated $\mathrm{S}$ calculated with PRIMER. (B) Non-metric multidimensional scaling ordinations of the presence-absence data of species on detached and anchored buoys. Arrows: those buoys that were colonized by only 1 sessile species and few mobile species.

(C) Percent of buoys with the respective range of species

The 10 most common associated taxa were found on $>60 \%$ of the detached and anchored buoys, respectively. These taxa comprised Ulva spp., the sessile species Pyura chilensis and Bugula neritina, and among the mobile species the polychaete Typosyllis magdalena, the amphipods Stenothoe sp. A, Paradexamine cf. pacifica, Caprella verrucosa and C. scaura, the tanaid Zeuxo cf. marmoratus and the brachyuran crab Pilumnoides perlatus. Recruits of Lepas spp. (<2 mm) were found on $45 \%$ and cypris larvae (most likely Lepas spp.) on $95 \%$ of the detached buoys. In contrast, recruits of Lepas spp. (<2 mm) and cypris larvae were not found on anchored buoys, although adult Lepas spp. were present on a few buoys (see Appendix 1).

The proportions of functional types among the invertebrates did not differ between detached and anchored buoys (Table 3). Fouling communities of both buoy categories were dominated by mobile species, suspension feeders, sexual reproduction, separate sexes, internal fertilization and direct development.

\section{Relationship between sessile and mobile species}

The sessile taxa with the highest biomasses were Ulva spp., Plumularia setacea, Austromegabalanus psittacus, Semimytilus algosus, Ciona intestinalis, Pyura chilensis, Bugula flabellata and $B$. neritina. These organisms are considered important eco-engineers for mobile organisms as also shown by a significant relationship between the numbers of sessile and mobile taxa on detached buoys $\left(t_{0.05(2), 20}=3.575, \mathrm{p}<0.001\right)$ (Fig. 5A). Similarly, a significant relationship between the biomass of sessile taxa and the number of mobile taxa was observed for detached buoys $\left(t_{0.05(2), 20}=3.923\right.$, $\mathrm{p}<0.0005$ ) (Fig. 5C). On anchored buoys, the relationship between sessile and mobile taxa was significant with the biomass of sessile species $\left(t_{0.05(2), 16}=2.723, \mathrm{p}<\right.$ $0.01)$, but not with the number of sessile species $\left(t_{0.05(2), 16}=1.515, \mathrm{p}>0.05\right)$ (Fig. 5B,D).

\section{DISCUSSION}

\section{Displacement of buoys}

Displacement direction and velocity of clean, floating buoys without rope were primarily affected by the wind, while buoys with rope mainly followed surface currents. This is similar to other objects such as life rafts, which respond to a combination of factors such as those intrinsic to the object (e.g. shape, area and presence/absence of a suspended drogue) and extrinsic factors such as wind force, surface currents and waves (Burciu 2002, Breivik $\&$ Allen 2008). The velocities of released buoys (0.2 to $1.9 \mathrm{~km} \mathrm{~h}^{-1}$ ) in proximity to the shore were within the range reported for macroalgae, wood, volcanic pumice and plastics (Harrold \& Lisin 1989, Thiel \& Gutow 2005a, Hernández-Carmona et al. 2006, Ingólfsson 2006). In general, the velocities and direction of buoys without rope corresponded to that of other floating items, which 
Table 3. Comparison between the proportions of species ( $n$, percentages given in parentheses) with different biological characteristics found on detached and anchored buoys. Chi-squared analyses of contingency tables are presented. See 'Materials and methods-Community composition and biological traits' for definitions of larval duration

\begin{tabular}{|c|c|c|c|c|c|c|}
\hline \multicolumn{2}{|l|}{ Functional type } & \multicolumn{2}{|c|}{$\begin{array}{c}\text { No. species } \\
\text { Detached Anchored }\end{array}$} & $\frac{d f}{2}$ & $\frac{\Sigma \chi^{2}}{1.593}$ & $\frac{p}{0.451}$ \\
\hline Motility & $\begin{array}{l}\text { Sessile } \\
\text { Semi-sessile } \\
\text { Mobile } \\
\text { Total no. species }\end{array}$ & $\begin{aligned} & 37(35) \\
& 2(2) \\
& 66(63) \\
& 105\end{aligned}$ & $\begin{array}{c}22(27) \\
1(1) \\
58(72) \\
81\end{array}$ & 2 & 1.593 & 0.451 \\
\hline Feeding & $\begin{array}{l}\text { Deposit-feeders } \\
\text { Suspension-feeders } \\
\text { Grazer/borer } \\
\text { Predator/scavenger } \\
\text { Total no. species }\end{array}$ & $\begin{array}{c}6(6) \\
48(46) \\
8(7) \\
43(41) \\
105\end{array}$ & $\begin{aligned} 2 & (2) \\
40 & (50) \\
& (9) \\
31 & (39) \\
& 80\end{aligned}$ & 3 & 1.387 & 0.709 \\
\hline Reproduction & $\begin{array}{l}\text { Sexual } \\
\text { Sexual/asexual } \\
\text { Total no. species }\end{array}$ & $\begin{array}{c}64(61) \\
41(39) \\
105\end{array}$ & $\begin{array}{l}53(66) \\
27(34) \\
80\end{array}$ & 1 & 0.548 & 0.459 \\
\hline $\begin{array}{l}\text { Sexual } \\
\text { system }\end{array}$ & $\begin{array}{l}\text { Gonochoric } \\
\text { Hermaphroditic } \\
\text { Total no. species }\end{array}$ & $\begin{array}{c}66(67) \\
33(33) \\
99\end{array}$ & $\begin{array}{l}54(68) \\
25(32) \\
79\end{array}$ & 1 & 0.057 & 0.811 \\
\hline Fertilization & $\begin{array}{l}\text { Internal } \\
\text { External } \\
\text { Total no. species }\end{array}$ & $\begin{array}{c}71(70) \\
30(30) \\
101\end{array}$ & $\begin{array}{l}55(71) \\
23(29) \\
\quad 78\end{array}$ & 1 & 0.001 & 0.975 \\
\hline $\begin{array}{l}\text { Larval } \\
\text { duration }\end{array}$ & $\begin{array}{l}\text { Direct } \\
\text { Short } \\
\text { Intermediate } \\
\text { Long } \\
\text { Total no. species }\end{array}$ & $\begin{array}{c}23(31) \\
23(31) \\
19(25) \\
10(13) \\
75\end{array}$ & $\begin{array}{l}21(38) \\
14(25) \\
14(25) \\
7(12) \\
56\end{array}$ & 3 & 0.829 & 0.843 \\
\hline
\end{tabular}

are mainly driven by the wind (Aliani \& Molcard 2003, Muhlin et al. 2008). The wind acts mainly on those objects that have a large part of their volume above the water, in contrast to objects almost entirely submerged which are primarily affected by surface currents (Aliani \& Molcard 2003). The wind can also drive the surface currents (e.g. Ekman transport), acting indirectly on the displacement of submerged floating items (Harrold \& Lisin 1989, Burciu 2002).

The hypothetical trajectories of floating buoys during the $12 \mathrm{~h}$ preceding capture suggest that the majority of buoys had their origin in the BSC, especially in the bays of Tongoy and Guanaqueros where we estimated the presence of $\sim 300000$ anchored buoys for aquaculture purposes. The high abundance of stranded buoys on the beaches of these bays (authors' pers. obs.) indicates frequent detachment events of buoys in those areas. Predominant winds from the W and SW (Moraga \& Olivares 1993) may push most buoys onto nearby beaches reducing the possibility of long distance
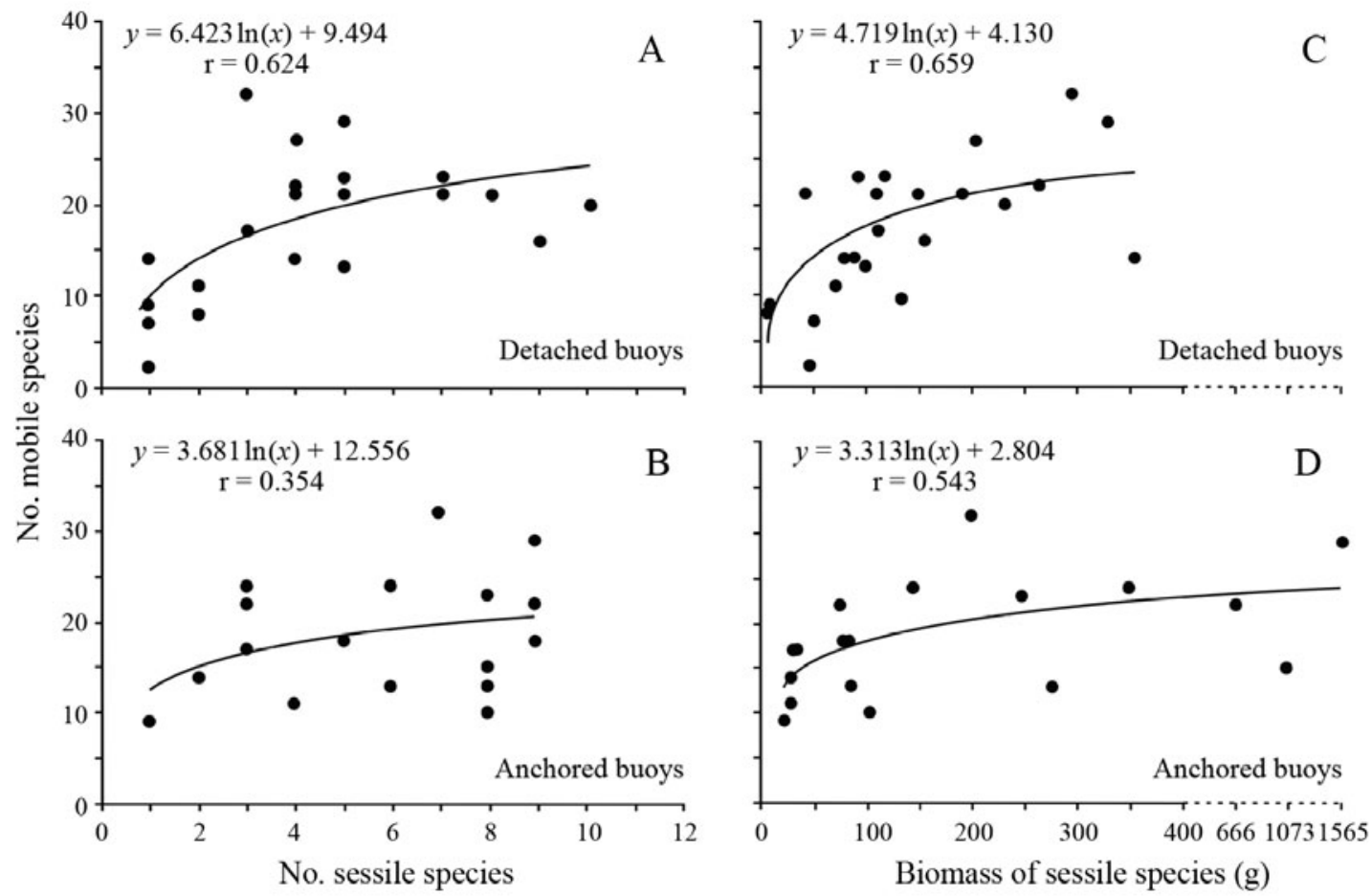

Fig. 5. Relationships between (A) numbers of sessile and mobile species on detached buoys, (B) numbers of sessile and mobile species on anchored buoys, (C) biomass of sessile species and number of mobile species on detached buoys and (D) biomass of sessile species and number of mobile species on anchored buoys. The number and biomass of sessile species includes only those species with wet weight $>1 \mathrm{~g}$ in each sample. Note change of $x$-axis scale (dashed line) for (C) and (D) 
trips. However, some buoys (especially those with rope) can be carried away from the coast and enter the Humboldt Current System where water masses move at a mean velocity of $\sim 1 \mathrm{~km} \mathrm{~h}^{-1}$ to the $\mathrm{N}$ and NW (Marín et al. 2003, Marín \& Delgado 2007). These buoys might travel over long distances within relatively short time periods (200 km in 10 d, see Marín \& Delgado 2007). Therefore, given the high potential of buoys to float for long time periods, the risk of longdistance dispersal of associated organisms should be cause for concern.

\section{Buoy-associated biota}

The biota on detached buoys (mainly from the phyla Arthropoda, Annelida and Mollusca) was similar to that on aquaculture buoys anchored in Bahía Tongoy. The taxa found on both types of buoys abound in fouling communities on aquaculture installations (Uribe et al. 2001, Pacheco \& Garate 2005) and on ship hulls (Farrapeira et al. 2007, Mineur et al. 2007). Many of the species from the buoys had been previously reported as fouling species in Bahía Tongoy (Uribe et al. 2001) and Bahía La Herradura (Valdivia et al. 2005). The presence of the scallop Argopecten purpuratus (cultured in Tongoy and Guanaqueros), the macroalga Codium fragile (reported for $30^{\circ} \mathrm{S}$, Neill et al. 2006) and the seagrass Heterozostera tasmanica (reported in Chile only at $27.6^{\circ} \mathrm{S}$ and $30.2^{\circ} \mathrm{S}$, González \& Edding 1990) on the detached buoys furthermore suggest that they come from the BSC. The small fragments of the seagrass $H$. tasmanica most likely became entangled with the buoys during the journey. The abundance of a number of non-indigenous species, including Ciona intestinalis, Bugula neritina, B. flabellata and Codium fragile (frequencies of occurrence of $73,82,59$ and $9 \%$, respectively), on the detached buoys should also be noted. These species have been catalogued as invasive species for the Chilean coast (Castilla et al. 2005), and our results suggest that detached buoys may represent an important dispersal vector, possibly contributing to the spread of these invaders.

The number of mobile species on buoys was positively related to the number and biomass of sessile species (see also Tsikhon-Lukanina et al. 2001). Sessile species might act as eco-engineers on buoys, offering structural support and refuge for mobile species (Cerda \& Castilla 2001, Sepúlveda et al. 2003, Hauser et al. 2006). Thus, an increase of biomass and number of sessile species enhances the diversity of structures to which mobile species can attach (see Fig. 5). These considerations underline the importance of sessile species in facilitating colonization and dispersal of mobile species on floating items.
Contrary to expectations, we observed no reduction of mobile species that could have escaped early in the detachment process, which is often the case immediately after detachment of macroalgae (Thiel 2003, Miranda \& Thiel 2008, Gutow et al. 2009). Instead, we found more mobile than sessile species on both detached and anchored buoys, which also contrasts with previous reports from plastic objects found on the beach (e.g. Winston et al. 1997, Barnes 2002), where the dominance of sessile species (with persistent calcareous structures) most likely has been overestimated. Mobile organisms may colonize buoys anchored in coastal waters via swimming or crawling of adults and planktonic larvae (Grantham et al. 2003) or drifting in the water column by small individuals (Page et al. 2006, Cañete et al. 2007).

While our results indicate that the proportion of mobile species might have been underestimated in previous studies, they confirm that suspension-feeders and species with the absence of planktonic larvae (i.e. with asexual reproduction or direct development) are favoured on floating plastics. Suspension-feeders (ascidians, barnacles, bivalves and bryozoans) were the most common species (number and biomass) on detached and anchored buoys, certainly because they benefited from favourable currents and food environments on bivalve aquaculture installations. There were also relatively large proportions of herbivores and carnivores, which probably feed on sessile species, macroalgae and their associated mobile organisms (e.g. Il'in \& Roginskaya 1987, Sano et al. 2003, Thiel \& Gutow 2005b). Developmental modes (larval duration) of organisms on buoys were similar to those reported from hard-bottom environments (Grantham et al. 2003), hinting that both types of buoys were originally colonized in the vicinity of rocky shores. The high proportion $(\sim 60 \%)$ of species with direct development or short larval durations, which are capable of maintaining persistent populations on floating items, suggests a high potential for long-distance dispersal of the fauna on buoys. Direct development (e.g. Johannesson 1988, Colson \& Hughes 2004) and short larval duration (Ó Foighil et al. 1989, Parker \& Tunnicliffe 1994) have been repeatedly inferred to favour rafting dispersal.

\section{Successional stages of fouling communities on detached buoys}

Extensive fouling communities can develop on buoys anchored in coastal waters (Uribe et al. 2001). Initial successional stages of fouling communities on plastics comprise mainly fast-growing algae (primarily Chlorophyta) followed by a stage with a high abundance of erect bryozoans and hydrozoans (Ye \& Andrady 1991). 
During intermediate stages of succession, barnacles may temporarily become dominant in fouling communities (e.g. Cifuentes et al. 2007), herein possibly represented by the high proportion of buoys with the barnacle Austromegabalanus psittacus $(50 \%$ of all sampled buoys). Later, barnacles are often overgrown by competitively superior organisms (e.g. Paine \& Suchanek 1983, Tokeshi \& Romero 1995), which are represented by the ascidian Pyura chilensis and the bivalve Semimytilus algosus in fouling communities from northern-central Chile (Valdivia et al. 2005, Cifuentes et al. 2007). The latter 2 species appeared on $>50 \%$ of the detached buoys in the present study, indicating the advanced successional stages of the fouling communities. Detached buoys with these dominant species had likely been in the water for several months, where they would have experienced strong winds and deterioration of ropes, which might have contributed to their detachment. Many original colonizers likely persisted on the floating buoys after detachment but also many new colonizers appeared, as indicated by the high proportion of rare species occurring only once on detached buoys. On many detached buoys we also found large numbers of individuals from the genus Lepas, which are characteristic colonizers on floating objects (Jara \& Jaramillo 1979, Macaya et al. 2005, Hinojosa et al. 2006). The high proportion of cypris larvae and small individuals of Lepas spp. $(<2 \mathrm{~mm})$ indicates that the detached buoys had been afloat for very short time periods (see Macaya et al. 2005), furthermore hinting at their local origin. These species may slowly start to dominate on floating objects when drifting for long time periods.

\section{Implications for rafting}

Although the availability of buoys in the oceans is lower than that of other plastics (e.g. bags, bottles, nets and ropes), the continuing expansion of aquaculture, tourism and harbour activities suggests an increasing abundance of these objects in the oceans. Buoys, in contrast to other plastic items, are characterized by their high buoyancy, durability and diverse fouling communities with many organisms (including nonindigenous species) that are adapted to the conditions at the sea surface. Upon detachment, these buoys are driven by winds and surface currents. Some buoys might be transported over long distances (100s of $\mathrm{km}$ ) with implications for regional and oceanic dispersal of associated organisms (Jara \& Jaramillo 1979, Jokiel 1989, Scarabino 2004), similar to other plastics (Winston 1982, Mora et al. 2001, Aliani \& Molcard 2003). These considerations suggest that rafting on buoys might facilitate long-distance dispersal of some associ- ated organisms that are capable of maintaining persistent populations (via reproduction and local recruitment) on floating items. Since detached buoys contain a large number of non-indigenous species, the problem of buoy losses from aquaculture facilities is of particular concern.

Acknowledgements. We are especially grateful to J. Moraga for his help in estimating dispersal vectors necessary to infer the possible origin of the detached buoys, and to J. Rutllant for providing some of the wind data. Further, we thank E. Macaya, W. Stotz, M. Romero, M. Valdebenito, D. Lancellotti, M. Schrödl, D. Veliz, N. Rozbaczylo, F. Diaz, L. Miranda and I. Hinojosa for their help with species identification. Three anonymous reviewers offered many constructive suggestions, which helped to substantially improve the manuscript. Funding was provided by FONDECYT 1010356 to M.T. and by FONDECYT 3070048 to C.P.D.

\section{LITERATURE CITED}

Aliani S, Molcard A (2003) Hitch-hiking on floating marine debris: macrobenthic species in the Western Mediterranean Sea. Hydrobiologia 503:59-67

Barnes DK (2002) Invasions by marine life on plastic debris. Nature 416:808-809

Barnes DK, Milner P (2005) Drifting plastic and its consequences for sessile organism dispersal in the Atlantic Ocean. Mar Biol 146:815-825

Breivik Ø, Allen A (2008) An operational search and rescue model for the Norwegian Sea and the North Sea. J Mar Syst 69:99-113

Burciu Z (2002) Application of Fokker-Planck equation for modeling the search and rescue area at sea. Annu Navig $4: 21-32$

- Cañete JI, Gallardo CS, Romero M, Ambler R (2007) Planktonic drifting dispersal of early juvenile Trochita calyptraeaformis Born 1778 (Gastropoda: Calyptraeidae). J Exp Mar Biol Ecol 346:1-7

> Castilla JC, Uribe M, Bahamonde N, Clarke M and others (2005) Down under the southeastern Pacific: marine nonindigenous species in Chile. Biol Invasions 7:213-232

Cerda M, Castilla JC (2001) Diversidad y biomasa de macroinvertebrados en matrices intermareales del tunicado Pyura praeputialis (Heller, 1872) en la Bahía de Antofagasta, Chile. Rev Chil Hist Nat 74:841-853 (with English Abstract)

Cifuentes M, Kamlah C, Thiel M, Lenz M, Wahl M (2007) Effects of temporal variability of disturbance on the succession in marine fouling communities in northern-central Chile. J Exp Mar Biol Ecol 352:280-294

Clarke KR, Warwick RM (1994) Change in marine communities: an approach to statistical analysis and interpretation, 1st edn. Plymouth Marine Laboratory

Cocito S (2004) Bioconstruction and biodiversity: their mutual influence. Sci Mar 68:137-144

Colson I, Hughes RN (2004) Rapid recovery of genetic diversity of dogwhelk (Nucella lapillus L.) populations after local extinction and recolonization contradicts predictions from life-history characteristics. Mol Ecol 13:2223-2233

> Derraik JGB (2002) The pollution of the marine environment by plastic debris: a review. Mar Pollut Bull 44:842-852

Ebbesmeyer CC, Ingraham JW Jr (1992) Shoe spill in the North Pacific. EOS Trans Am Geophys Union 73:361-368 
Farrapeira CMR, Melo AVOM, Barbosa DF, Silva KME (2007) Ship hull fouling in the Port of Recife, Pernambuco. Braz J Oceanogr 55:207-221

Fujieda S, Sasaki K (2005) Stranded debris of foamed plastics on the coast of Eta Island and Kurahashi Island in Hiroshima Bay. Nippon Suisan Gakkai Shi 71:755-761

> González SA, Edding ME (1990) Extension of the range of Heterozostera tasmanica (Martens ex Aschers.) den Hartog in Chile. Aquat Bot 38:391-395

Grantham B, Eckert GL, Shanks AL (2003) Dispersal potential of marine invertebrates in diverse habitats. Ecol Appl 13:108-116

Greene JK, Grizzle RE (2007) Successional development of fouling communities on open ocean aquaculture fish cages in the western Gulf of Maine, USA. Aquaculture 262:289-301

Gregory MR, Andrady AL (2003) Plastics in the marine environment. In: Andrady AL (ed) Plastics and the environment. John Wiley, Hoboken, NJ, p 379-401

> Gutow L, Giménez L, Boos K, Saborowski R (2009) Rapid changes in the epifaunal community after detachment of buoyant benthic macroalgae. J Mar Biol Assoc UK 89: $323-328$

Harrold C, Lisin S (1989) Radio-tracking rafts of giant kelp: local production and regional transport. J Exp Mar Biol Ecol 130:237-251

Hauser A, Attrill MJ, Cotton PA (2006) Effects of habitat complexity on the diversity and abundance of macrofauna colonising artificial kelp holdfasts. Mar Ecol Prog Ser 325: 93-100

Hernández C, Muñoz G, Rozbaczylo N (2001) Poliquetos asociados con Austromegabalanus psittacus (Molina 1782) (Crustacea: Cirripedia) en península Gualpén, en Chile central: biodiversidad y efecto del tamaño del sustrato biológico. Rev Biol Mar Oceanogr 36:99-108 (with English Abstract)

> Hernández-Carmona G, Hughes B, Graham MH (2006) Reproductive longevity of drifting kelp Macrocystis pyrifera (Phaeophyceae) in Monterey Bay, USA. J Phycol 42:1199-1207

> Hinojosa IA, Thiel M (2009) Floating marine debris in fjords, gulfs and channels of southern Chile. Mar Pollut Bull 58: 341-350

Hinojosa I, Boltaña S, Macaya E, Ugalde P and others (2006) Geographic distribution and description of four pelagic barnacles along the south east Pacific coast of Chile: a zoogeographical approximation. Rev Chil Hist Nat 78:603-614

Il'in IN, Roginskaya IS (1987) Mollusks: Nudibranchia in pelagic epifauna of solid substrata. In: Kuznetsov AP, Sokolova MN (eds) Feeding of marine invertebrates and its role in community formation. Acad Sci USSR, Shirshov Inst Oceanol, Moscow, p 72-75

Ingólfsson A (2006) The intertidal seashore of Iceland and its animal communities. Zool Iceland 1:1-85

Ivar do Sul JA, Costa MF (2007) Marine debris review for Latin America and the wider Caribbean region: from the 1970s until now, and where do we go from here? Mar Pollut Bull 54:1087-1104

Jara C, Jaramillo E (1979) Hallazgo de Planes marinus Rathbun, 1914, sobre boya a la deriva en bahía de Maquillahue Chile (Crustácea. Decapoda, Grapsidae). Medio Ambiente 4:108-113

Johannesson K (1988) The paradox of Rockall: Why is a brooding gastropod (Littorina saxatilis) more widespread than one having a planktonic larval dispersal stage (Littorina littorea)? Mar Biol 99:507-513

Jokiel PL (1989) Rafting of reef corals and other organisms at
Kwajalein Atoll. Mar Biol 101:483-493

Macaya EC, Boltaña S, Hinojosa IA, Macchiavello JE and others (2005) Presence of sporophylls in floating kelp rafts of Macrocystis spp. (Phaeophyceae) along the Chilean pacific coast. J Phycol 41:913-922

> Marín VH, Delgado LE (2007) Lagrangian observations of surface coastal flows North of $30^{\circ} \mathrm{S}$ in the Humboldt Current system. Cont Shelf Res 27:731-743

> Marín VH, Delgado LE, Luna-Jorquera G (2003) S-chlorophyll squirts at $30^{\circ} \mathrm{S}$ off the Chilean coast (eastern South Pacific): feature-tracking analysis. J Geophys Res C 108:3378

> Mineur F, Johnson MP, Maggs CA, Stegenga H (2007) Hull fouling on commercial ships as a vector of macroalgal introduction. Mar Biol 151:1299-1307

Miranda L, Thiel M (2008) Active and passive migration in boring isopods Limnoria spp. (Crustacea, Peracarida) from kelp holdfasts. J Sea Res 60:176-183

Mora C, Francisco V, Zapata F (2001) Dispersal of juvenile and reef fishes associated with floating objects and their recruitment into Gorgona Island reefs, Colombia. Bull Mar Sci 68:557-561

Moraga J, Olivares J (1993) Condiciones oceanográficas del área próxima a la costa frente a Coquimbo, Chile. Publ Ocas Facultad Ciencias del Mar, UC del Norte, Coquimbo, 2:125-140

Muhlin JF, Engel CR, Stessel R, Weatherbee RA, Brawley SH (2008) The influence of coastal topography, circulation patterns, and rafting in structuring populations of an intertidal alga. Mol Ecol 17:1198-1210

Neill PE, Alcalde O, Faugeron S, Navarrete SA, Correa JA (2006) Invasion of Codium fragile spp. tomentosoides in northern Chile: a new threat for Gracilaria farming. Aquaculture 259:202-210

Ó Foighil D (1989) Planktotrophic larval development is associated with a restricted geographic range in Lasaea, a genus of brooding, hermaphroditic bivalves. Mar Biol 103:349-358

Pacheco A, Garate A (2005) Bioincrustantes en estructuras de cultivo de Argopecten purpuratus en Bahía Samanco, Perú. Ecol Apl 4:149-152 (with English Abstract)

Page HM, Dugan JE, Culver CS, Hoesterey JC (2006) Exotic invertebrate species on offshore oil platforms. Mar Ecol Prog Ser 325:101-107

Paine RT, Suchanek TH (1983) Convergence of ecological processes between independently evolved competitive dominants; a tunicate-mussel comparison. Evolution 37: 821-831

> Parker T, Tunnicliffe V (1994) Dispersal strategies of the biota on an oceanic seamount: implications for ecology and biogeography. Biol Bull 187:336-345

Pruter AT (1987) Sources, quantities and distribution of persistent plastic in the marine environment. Mar Pollut Bull 18:305-310

Rutllant J, Montecino V (2002) Multiscale upwelling forcing cycles and biological response off northcentral Chile. Rev Chil Hist Nat 75:217-231

> Sano M, Omori M, Taniguchi K (2003) Predator-prey systems of drifting seaweed communities off the Tohoku coast, northern Japan, as determined by feeding habit analysis of phytal animals. Fish Sci 69:260-268

Scarabino F (2004) Two gastropods associated with floating objects from the Uruguayan coast. Comun Soc Malacol Urug 8:275-277

Sepúlveda R, Cancino JM, Thiel M (2003) The peracarid epifauna associated with the ascidian Pyura chilensis (Molina, 1782) (Ascidiacea: Pyuridae). J Nat Hist 37:1555-1569

Stevens LM, Gregory MR, Foster BA (1996) Fouling bry- 
ozoans on pelagic and moored plastics from northern New Zealand. In: Gordon DP, Smith AM, Grant-Mackie JA (eds) Bryozoans in space and time. NIWA, Wellington, p 321-340

Thiel M (2003) Rafting of benthic macrofauna: important factors determining the temporal succession of the assemblage on detached macroalgae. Hydrobiologia 503:49-57

Thiel M, Gutow L (2005a) The ecology of rafting in the marine environment. I. The floating substrata. Oceanogr Mar Biol Annu Rev 42:181-264

Thiel M, Gutow L (2005b) The ecology of rafting in the marine environment. II. The rafting organisms and community. Oceanogr Mar Biol Annu Rev 43:279-418

Thiel M, Guerra-García JM, Lancellotti D, Vásquez N (2003a) The distribution of littoral caprellids (Crustacea: Amphipoda: Caprellidea) along the Pacific coast of continental Chile. Rev Chil Hist Nat 76:297-312

Thiel M, Hinojosa I, Vásquez N, Macaya E (2003b) Floating marine debris in coastal waters of the SE-Pacific (Chile). Mar Pollut Bull 46:224-231

Tokeshi M, Romero L (1995) Filling a gap: dynamics of space occupancy on a mussel-dominated subtropical rocky shore. Mar Ecol Prog Ser 119:167-176

Tsikhon-Lukanina EA, Reznichenko OG, Nikolaeva GG (2001) Ecology of invertebrates on the oceanic floating substrata in the Northwest Pacific Ocean. Russ Acad Sci Oceanol 41:525-530

Editorial responsibility: Sean Connell, Adelaide, Australia
Uribe E, Lodeiros C, Felix-Pico E, Etchepare I (2001) Epibiontes en pectínidos de Iberoamerica. In: MaedaMartínez AN (ed) Los Moluscos pectínidos de Iberoamerica: Ciencias y Acuicultura. Editorial Limusa, México, p 249-266

Valdivia N, Heidemann A, Thiel M, Molis M, Wahl M (2005) Effects of disturbance on the diversity of hard-bottom macrobenthic communities on the coast of Chile. Mar Ecol Prog Ser 299:45-54

Valle-Levinson A, Moraga J (2006) Observations of bipolar residual circulation in two equatorward-facing semiarid bays. Cont Shelf Res 26:179-193

> Valle-Levinson A, Moraga J, Olivares J, Blanco JL (2000) Tidal and residual circulation in a semi-arid bay: Coquimbo Bay, Chile. Cont Shelf Res 20:2009-2028

- Winston JE (1982) Drift plastic: an expanding niche for a marine invertebrate. Mar Pollut Bull 13:348-351

Winston JE, Gregory MR, Stevens LM (1997) Encrusters, epibionts, and other biota associated with pelagic plastics: a review of biogeographical, environmental, and conservation issues. In Coe JM, Rogers DB (eds) Marine debris: sources, impacts, and solution. Springer, New York, p 81-97

- Ye S, Andrady AL (1991) Fouling of floating plastic debris under Biscayne Bay exposure conditions. Mar Pollut Bull 22:608-613

Zar JH (1999) Biostatistical analysis, 4th edn. Prentice Hall, Upper Saddle River, NJ

Submitted: April 9, 2008; Accepted: March 20, 2009 Proofs received from author(s): May 4, 2009 